Supporting information

\title{
In Situ Growth Large Area Silver Nanostructure on Metal Phenolic Network Coated NAAO Film and Its SERS Sensing Application for Monofluoroacetic Acid
}

Jiefang Sun ${ }^{1}$, Dingshuai Xue ${ }^{2}$, Wenchong Shan ${ }^{3}$, Rui Liu ${ }^{4}$, Runqing Liu ${ }^{5}$, Huachao Zhao $^{4}$, Ting $\mathrm{Li}^{1}$, Zhanhui Wang ${ }^{3}$, Jing Zhang ${ }^{1}$, Bing Shao ${ }^{* 1,3,5}$

${ }^{1}$ Beijing Key Laboratory of Diagnostic and Traceability Technologies for Food poisoning, Beijing Center for Disease Prevention and Control, Beijing 100013, China ${ }^{2}$ State Key Laboratory of Lithospheric Evolution, Institute of Geology and Geophysics, Chinese Academy of Sciences, Beijing 100029, China

${ }^{3}$ College of Veterinary Medicine, China Agricultural University, Beijing 100193, China

${ }^{4}$ State Key Laboratory of Environmental Chemistry and Ecotoxicology, Research Center for Eco-Environmental Sciences, Chinese Academy of Sciences, Beijing 100085, China

${ }^{5}$ School of Public Health, Capital Medical University, Beijing 100069, China

${ }^{*}$ Corresponding author: Bing Shao, E-mail: shaobingch@sina.com

Key words:

Surface-enhanced Raman spectroscopy; Monofluoroacetic acid; Silver nanostructure; Anodic aluminium oxidation film; Metal phenolic network 


\section{Preparation of real samples}

The crude food and biological samples for this research were prepared from diluted human serum, fresh chicken and drinking water. The chicken were weighted and diluted with the methanol/formic acid mixed solution (9:1) homogenized for 5 min following by centrifuging for $2 \mathrm{~min}$ at 1,2000 rpm to remove large residual, and then the supernatant liquid was collected and spiked with FAcOH to 100 and $300 \mathrm{nmol} \mathrm{L}^{-1}$ for testing. The human serum was diluted 10 times with the methanol/formic acid mixed solution (9:1) before analysis, and following by centrifuging for 2 min at 1,2000 rpm to remove proteins, and then the supernatant liquid was collected and spiked with FAcOH to 100 and $300 \mathrm{nmol} \mathrm{L}^{-1}$ for testing. Drinking water was used as it received.
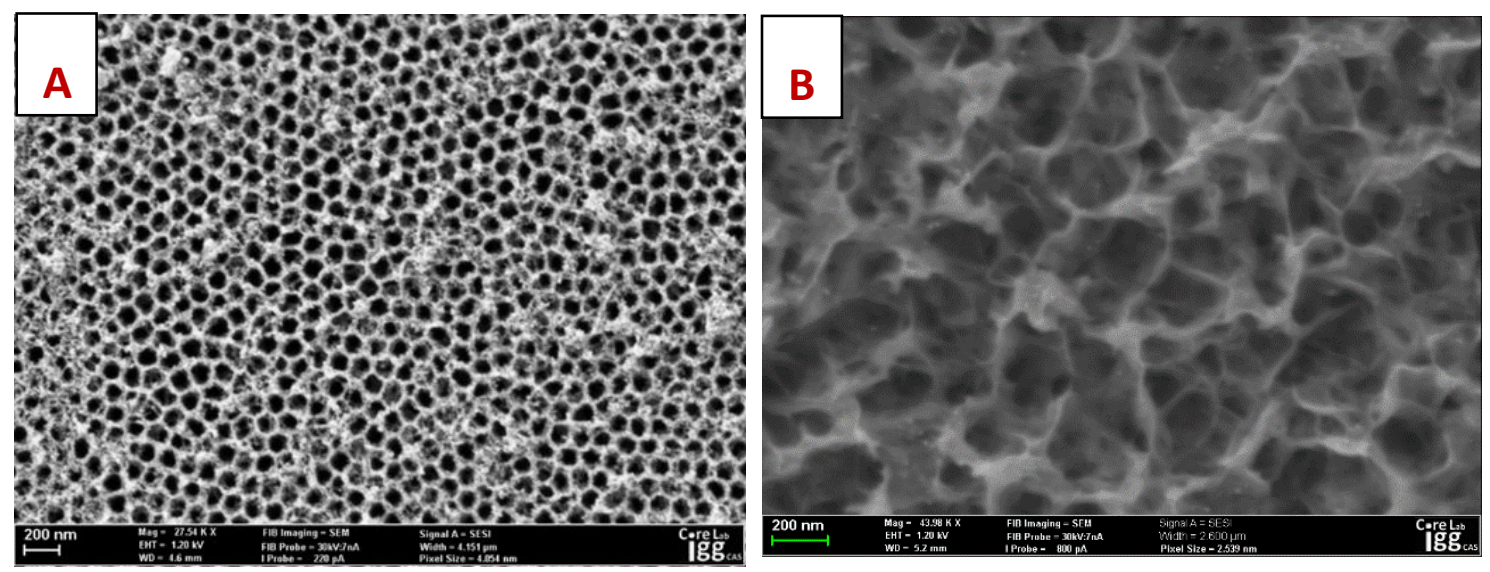

Figure S1. SEM of (A) the AgNPs generated on the NAAO@TA and (B) the AgNS formed on the NAAO@TA/Fe ${ }^{3+}$. 


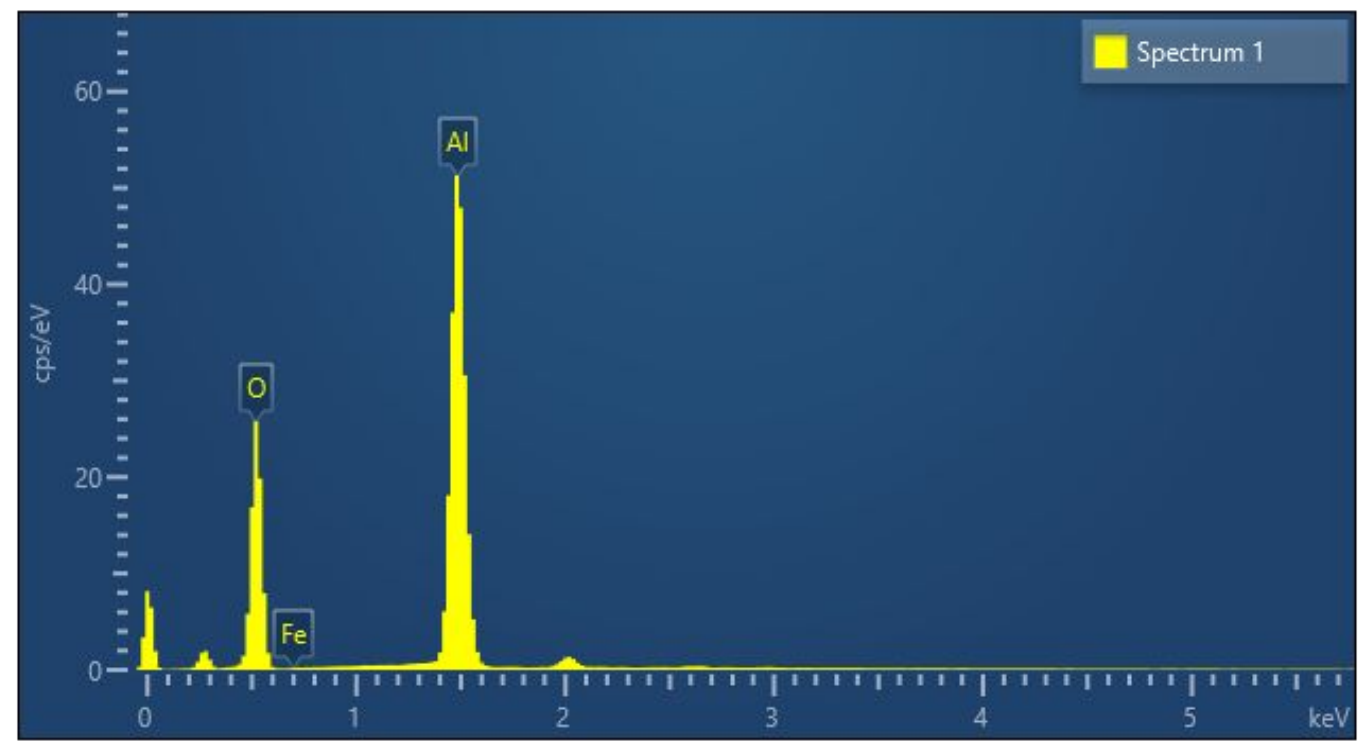

\begin{tabular}{|l|c|r|r|r|r|r|c|}
\hline Element & $\begin{array}{c}\text { Line } \\
\text { Type }\end{array}$ & $\begin{array}{c}\text { Apparent } \\
\text { Concentration }\end{array}$ & $\mathrm{k}$ Ratio & $\mathrm{Wt} \%$ & $\begin{array}{c}\mathrm{Wt} \% \\
\text { Sigma }\end{array}$ & $\begin{array}{c}\text { Standard } \\
\text { Label }\end{array}$ & $\begin{array}{c}\text { Factory } \\
\text { Standard }\end{array}$ \\
\hline $\mathrm{O}$ & $\begin{array}{c}\mathrm{K} \\
\text { series }\end{array}$ & 31.48 & 0.27580 & 47.04 & 0.19 & $\mathrm{SiO} 2$ & Yes \\
\hline $\mathrm{Al}$ & $\begin{array}{c}\mathrm{K} \\
\text { series }\end{array}$ & 56.27 & 0.50986 & 52.73 & 0.20 & $\mathrm{~A} 2 \mathrm{O} 3$ & Yes \\
\hline $\mathrm{Fe}$ & $\begin{array}{c}\mathrm{K} \\
\text { series }\end{array}$ & 0.24 & 0.00240 & 0.23 & 0.12 & $\mathrm{Fe}$ & Yes \\
\hline Total: & & & & 100.00 & & & \\
\hline
\end{tabular}

Figure S2. EDS analysis report for the TA modified NAAO (the NAAO@TA) 


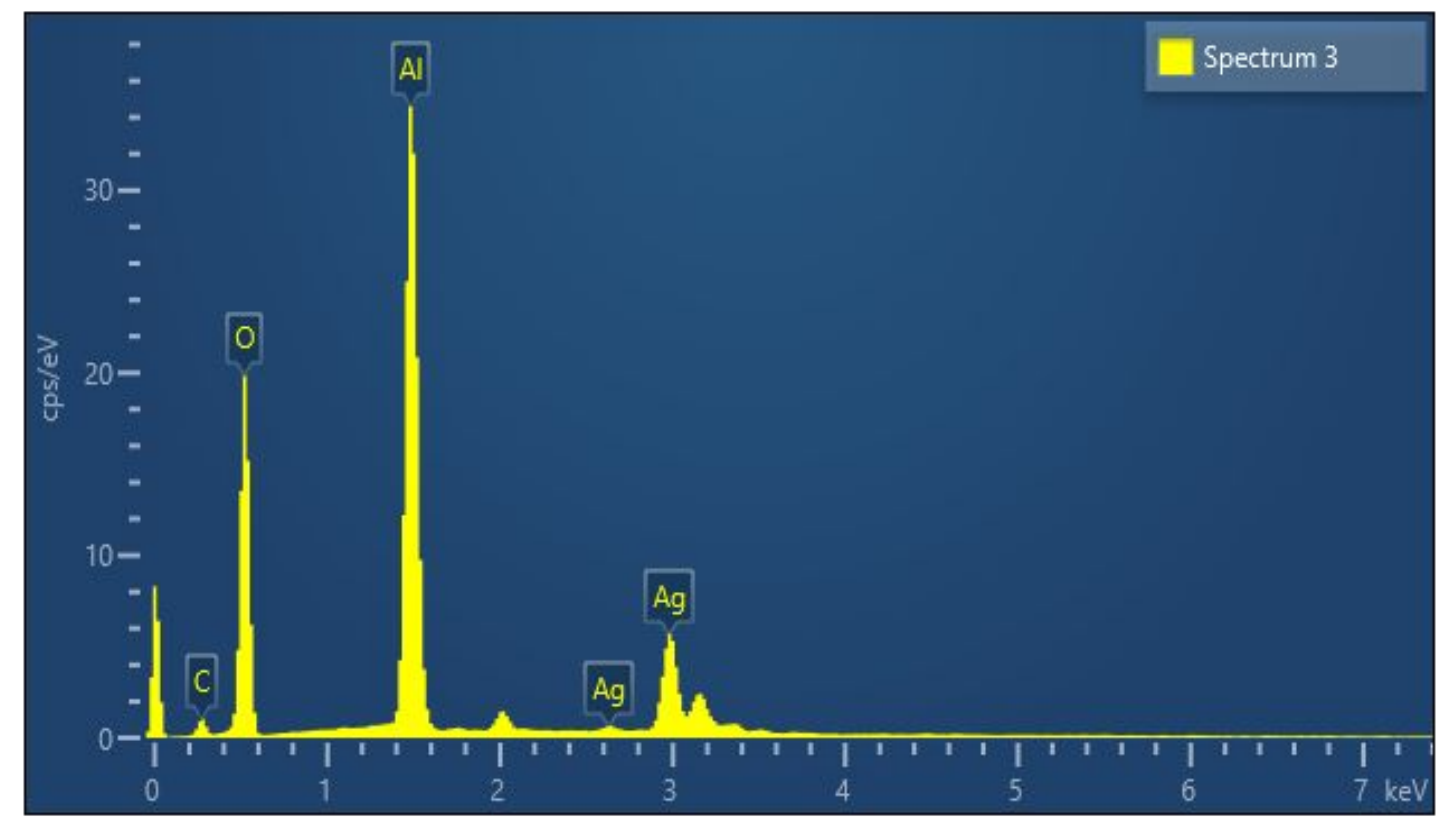

\begin{tabular}{|l|c|r|r|r|r|r|c|}
\hline Element & $\begin{array}{c}\text { Line } \\
\text { Type }\end{array}$ & $\begin{array}{c}\text { Apparent } \\
\text { Concentration }\end{array}$ & k Ratio & $\mathrm{Wt} \%$ & $\begin{array}{c}\mathrm{Wt} \% \\
\text { Sigma }\end{array}$ & $\begin{array}{c}\text { Standard } \\
\text { Label }\end{array}$ & $\begin{array}{c}\text { Factory } \\
\text { Standard }\end{array}$ \\
\hline $\mathrm{C}$ & $\begin{array}{c}\mathrm{K} \\
\text { series }\end{array}$ & 1.61 & 0.01605 & 4.75 & 0.22 & Pure Element & Yes \\
\hline $\mathrm{O}$ & $\begin{array}{c}\mathrm{K} \\
\text { series }\end{array}$ & 25.02 & 0.21922 & 44.78 & 0.24 & $\mathrm{SiO} 2$ & Yes \\
\hline $\mathrm{Al}$ & $\begin{array}{c}\mathrm{K} \\
\text { series }\end{array}$ & 38.78 & 0.35143 & 31.85 & 0.18 & $\mathrm{Al} 2 \mathrm{O} 3$ & Yes \\
\hline $\mathrm{Ag}$ & $\begin{array}{c}\mathrm{L} \\
\text { series }\end{array}$ & 22.79 & 0.22795 & 18.62 & 0.20 & Pure Element & Yes \\
\hline Total: & & & & 100.00 & & & \\
\hline
\end{tabular}

Figure S3. EDS analysis report for the NAAO@AgNS1 

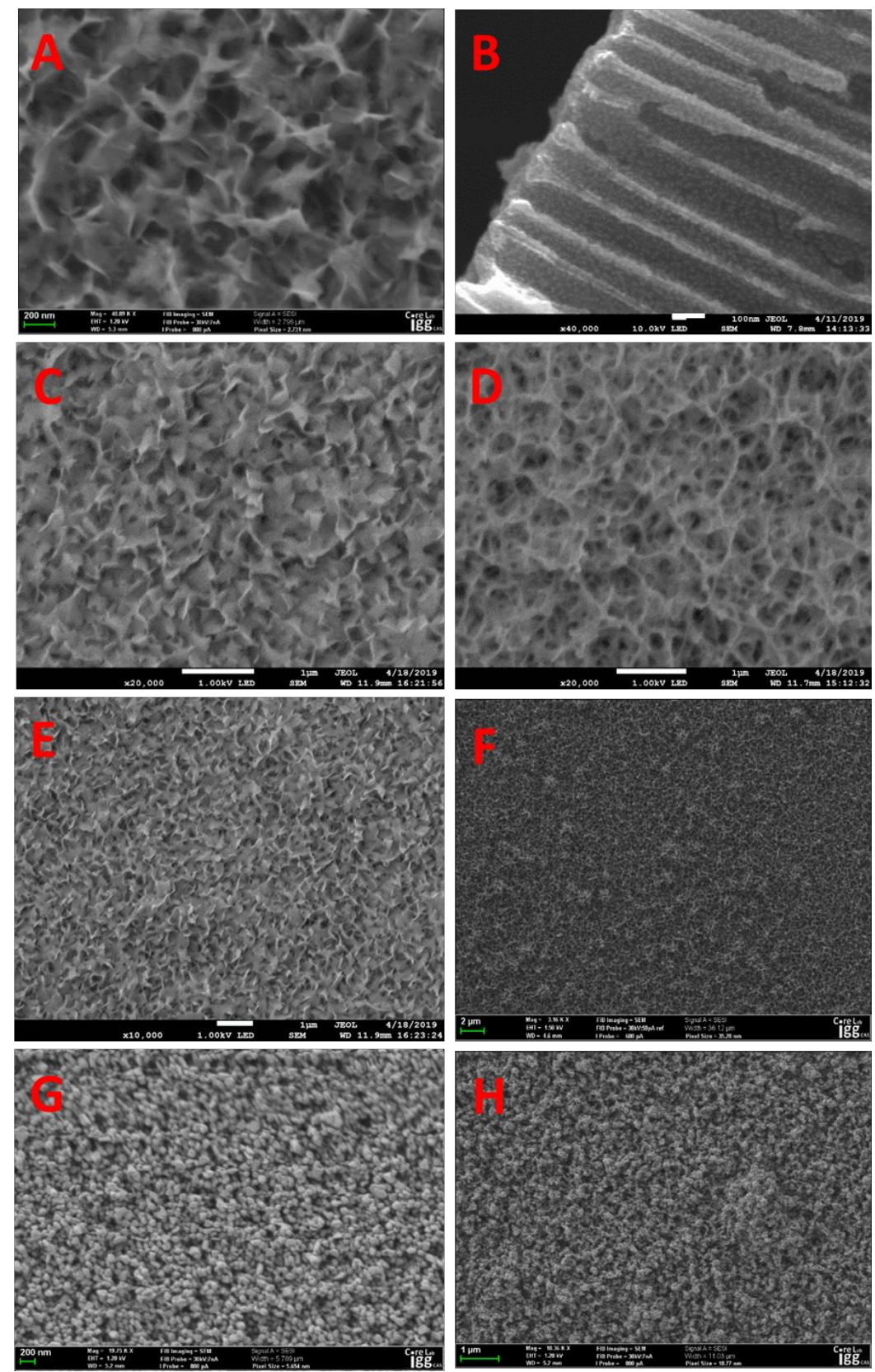

Figure S4. SEM image of (A) Ag deposition on the NAAO@TA, (B) AgNPs generated on the inner walls of vertical channels in the NAAO@AgNS1, (C and E) Ag nanostructures formed on the $\mathrm{NAAO}_{200} @ \mathrm{TA} / \mathrm{Fe}^{3+}$ (the $\left.\mathrm{NAAO}_{200} @ \mathrm{AgNS} 1\right)$ and further depositing AgNP on them (the $\mathrm{NAAO}_{200} @ \mathrm{AgNS} 2$ ), (D and F) Ag nanostructures formed on the $\mathrm{NAAO}_{50} @ \mathrm{TA} / \mathrm{Fe}^{3+}$ (the $\left.\mathrm{NAAO}_{50} @ \mathrm{AgNS} 1\right)$ and further depositing AgNP on them (the $\mathrm{NAAO}_{50} @ \mathrm{AgNS} 2$ ). Fabricating TA/Fe ${ }^{3+} \mathrm{MNPs}$ on the different sized NAAO as well subsequent Ag deposition were the same methods. 

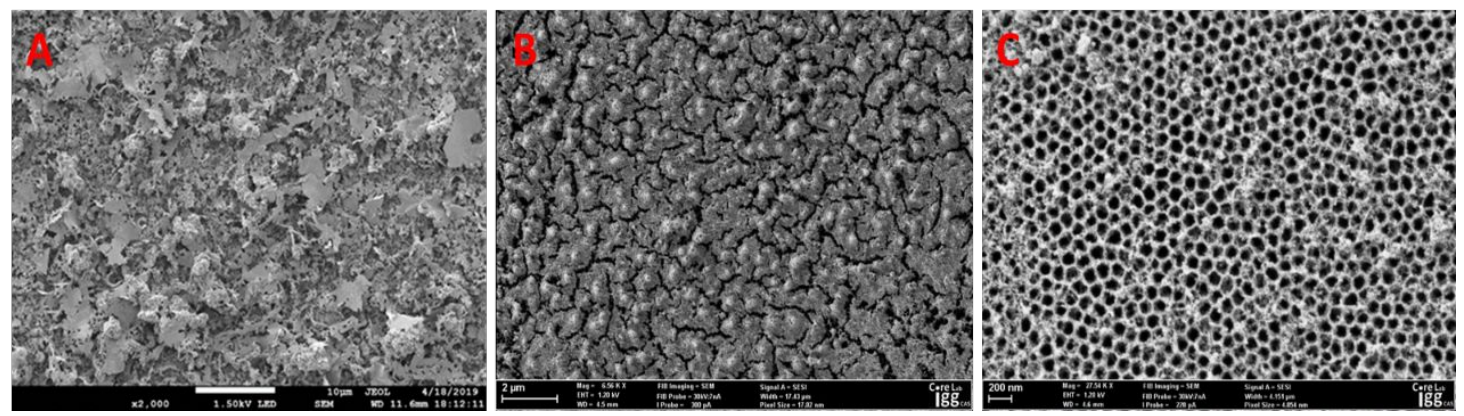

Figure S5. SEM images of Ag deposition on (A) the aluminium foil (B) the NAAO as well as $(\mathrm{C})$ the NAAO@TA.

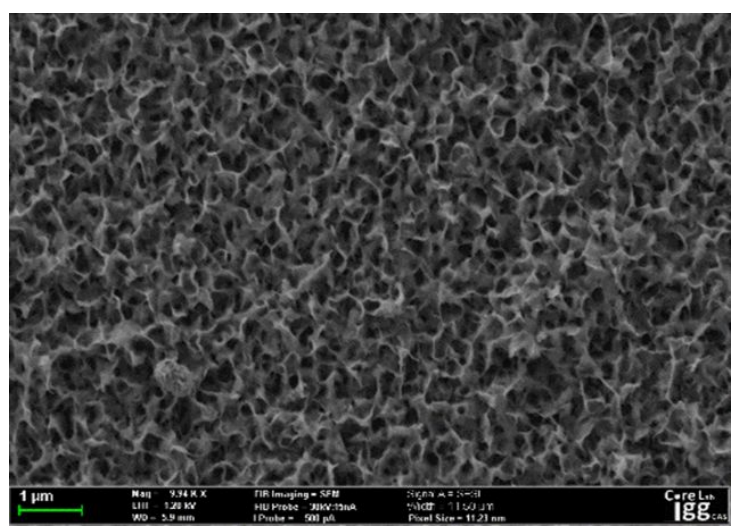

Figure S6. SEM image the NAAO@AgNS1 after incubating with $1 \mathrm{mmol} \mathrm{L}^{-1} \mathrm{NaOH}$ solution for $1 \mathrm{~h}$.
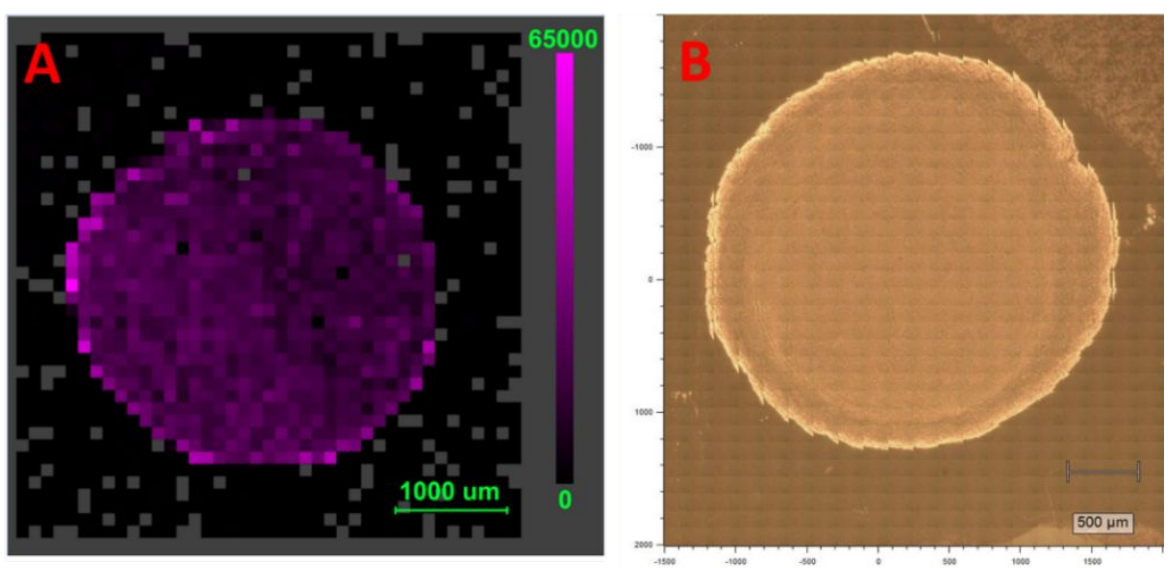

Figure S7. Examination of the "coffee-ring" effect on the NAAO@AgNS2. (A) SERS mapping image of the TSA-AuNPs (50 nm) formed on the NAAO@AgNS2; (B) Optical images collected using the Raman spectrometer.from the same view as that of SERS mapping image. 


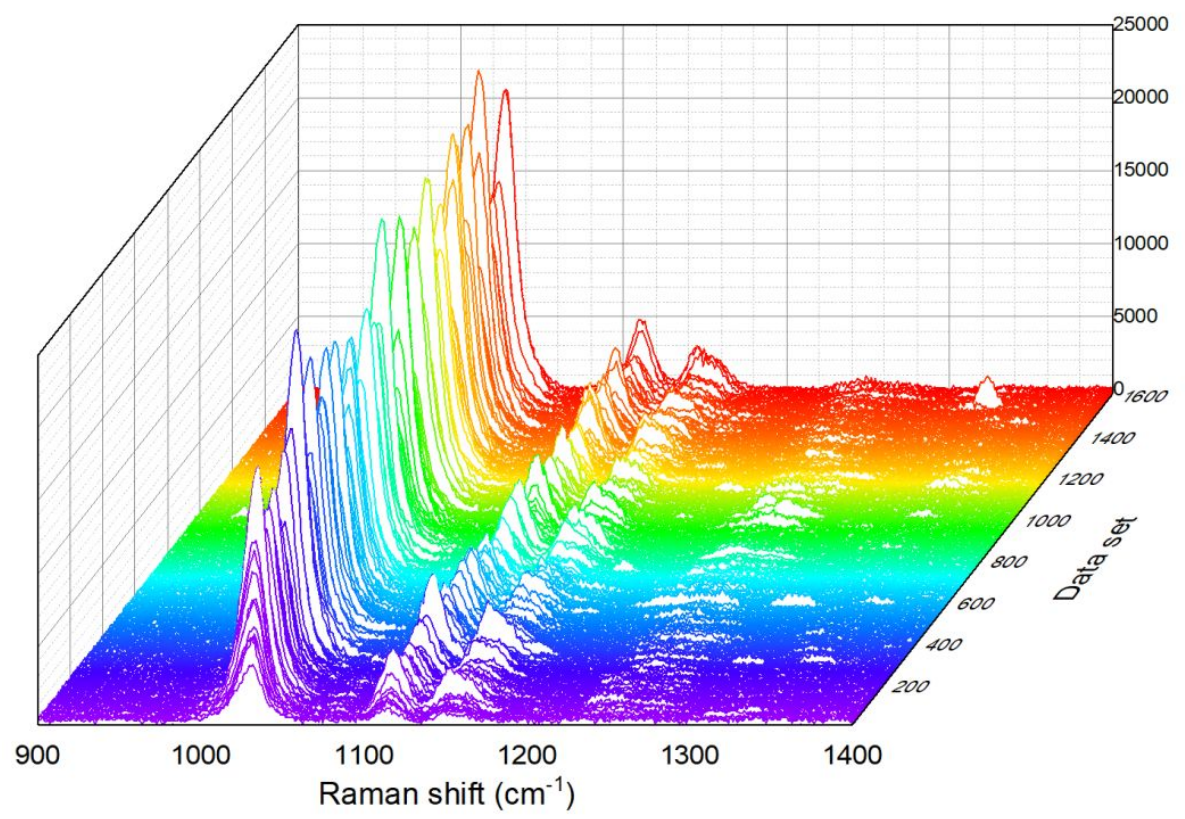

Figure S8. The raw Raman mapping data

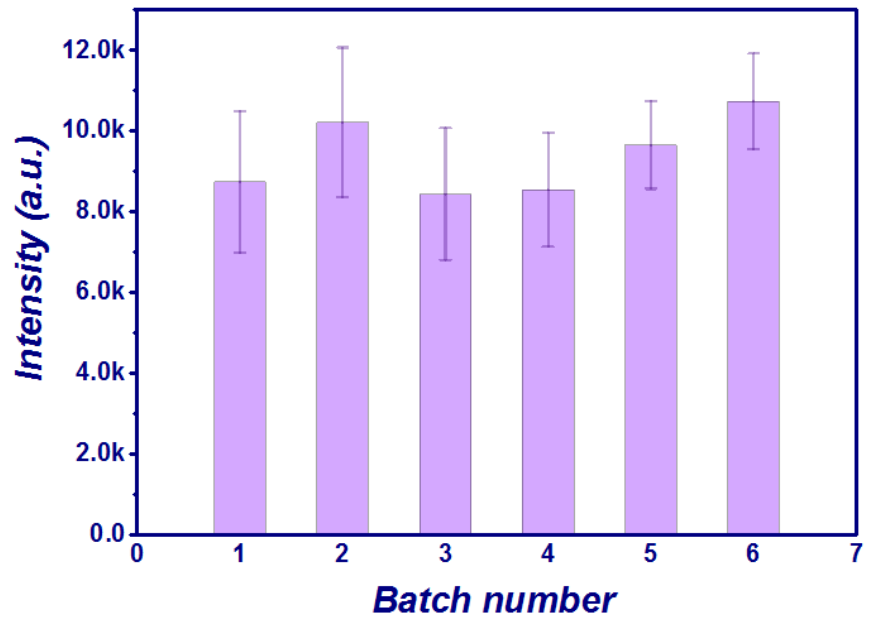

Figure S9. The SERS enhancement of different batch of the NAAO@AgNS2 
(1)

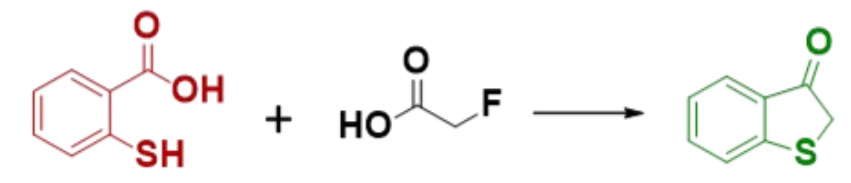

(2)

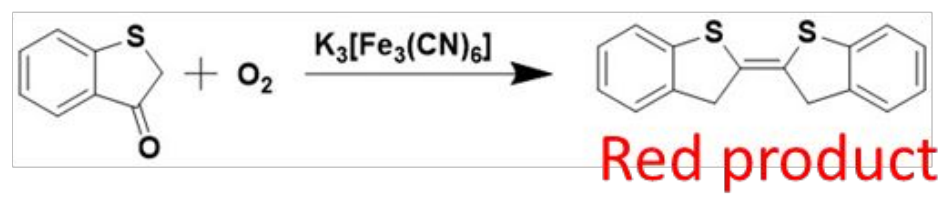

Figure S10 The thioindigo chromogenic reaction for $\mathrm{FAcOH}$ assay. 


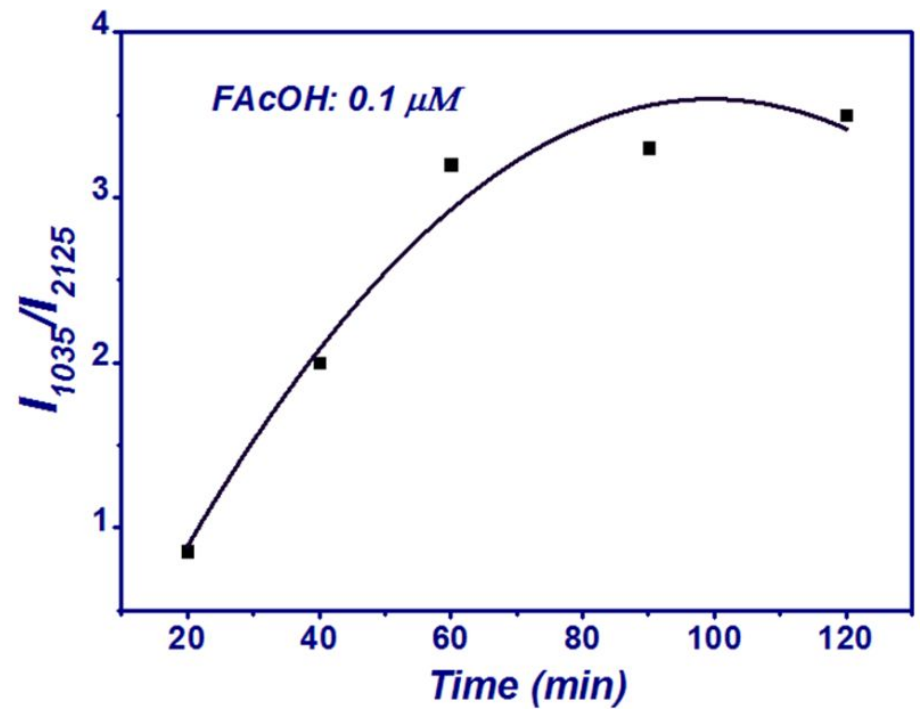

Figure S11 The adsorption equilibrium curve of the TSA on the NAAO@AgNS2. 